\title{
ESTRATÉGIAS DE APRENDIZAGEM EM FUNÇÃO DA FINALIDADE PARA O APRENDIZADO: UM ESTUDO COM TRABALHADORES DA LINHA DE PRODUÇÃO DE UMA EMPRESA DO RAMO AUTOMOTIVO
}

\author{
Eduardo Jardim Ushiro * \\ eduardojardimushiro@yahoo.com.br \\ Prof. Dr. Diógenes de Souza Bido* \\ diogenesbido@yahoo.com.br \\ *Universidade Presbiteriana Mackenzie - SP / Brasil
}

\author{
http://dx.doi.org/10.1590/1413-2311.05614102014.53645 \\ Recebido em 20/02/2015 \\ Aprovado em 24/03/2016 \\ Disponibilizado em 06/06/2016 \\ Avaliado pelo sistema "double blind review" \\ Revista Eletrônica de Administração \\ Editora-chefe: Aurora Zen \\ ISSN 1413-2311 (versão "on line") \\ Editada pela Escola de Administração da Universidade Federal do Rio Grande do Sul. \\ Periodicidade: Quadrimestral \\ Sistema requerido: Adobe Acrobat Reader
}

\section{RESUMO}

O aumento da competitividade tem forçado as organizações a se adaptarem e reinventarem constantemente. Esse contexto implica diretamente em motivos encontrados pelos indivíduos para aprender, como resolver um problema ou executar uma nova tarefa, levando os mesmos a utilizarem diferentes estratégias no processo de aprendizagem. As estratégias podem ter um caráter informal, como pedir ajuda aos colegas, pesquisar material escrito, ou formal, como participar de cursos e programas de qualificação oferecidos pela empresa. Este estudo procura mensurar e compreender quais estratégias de aprendizagem são mais utilizadas de acordo com quatro motivos distintos identificados no local de trabalho. A amostra foi composta por 463 profissionais que atuam na linha de produção de uma empresa do ramo automotivo. Foram realizadas análises fatoriais confirmatórias para se garantir a validade e confiabilidade das medidas, posteriormente, os escores fatoriais foram utilizados nas comparações do uso de cada estratégia de aprendizagem para cada finalidade (testes de Kruskal-Wallis e Wilcoxon). Os resultados demonstraram que as estratégias utilizadas não diferem conforme as quatro finalidades apresentadas. Dentre as estratégias pesquisadas, a mais utilizada é a ajuda interpessoal e as menos utilizadas são a consulta a material escrito e a participação em cursos e programas de treinamento formais oferecidos pela empresa.

Palavras-chave: Aprendizagem individual; Aprendizagem informal; Estratégias de aprendizagem. 
Eduardo Jardim Ushiro \& Diógenes de Souza Bido

\title{
LEARNING STRATEGIES ACCORDING TO THE PURPOSE FOR LEARNING: A STUDY WITH WORKERS IN THE PRODUCTION LINE OF AN AUTOMOTIVE COMPANY
}

\begin{abstract}
The growth of competitiveness has forced organizations to adapt and reinvent themselves constantly. This context implies directly in reasons found by the individuals to learn, like solving problems or performing a new task, for example, leading them to use different strategies for the learning process. Learning strategies may be informal, like asking for help to colleagues or reading a technical material. It may be also formal, like attending courses and taking part in training programs offered by the company. This study aims to measure and understand which learning strategies are mostly used according to four different reasons identified in the workplace. The sample consisted of 463 workers from the production line in an automotive company. Confirmatory factor analysis was applied to ensure the validity and the reliability of the measures subsequently, the factor scores were used in the comparisons of the use of each learning strategy for each purpose (Kruskal-Wallis and Wilcoxon) factor analyzes were performed. The results showed that the learning strategies applied do not differ according to the four objectives presented. Among the surveyed strategies, the most used is interpersonal help-seeking whereas written help-seeking and participation in courses and training programs offered by the company are less applied.
\end{abstract}

Keywords: Individual learning; Informal learning; Learning strategies.

ESTRATEGIAS DE APRENDIZAJE EN FUNCIÓN DE PROPÓSITO PARA EL APRENDIZAJE: UN ESTUDIO DE LOS TRABAJADORES EN LA LÍNEA DE
PRODUCCIÓN DE UNA EMPRESA DE AUTOMÓVILES

RESUMEN

El aumento de la competitividad ha obligado las organizaciones a adaptarse y reinventarse constantemente. Este contexto implica motivos directamente encontrados por los individuos a aprender a resolver un problema o realizar una nueva tarea, lo que lleva a utilizar diferentes estrategias en el proceso de aprendizaje. Las estrategias pueden tener un carácter informal, como pedir ayuda a los colegas, la escritura de investigación, formales o materiales, como la participación a cursos y programas de formación ofrecidos por la empresa. Esta pesquisa busca medir y comprender que estrategias de aprendizaje son los más utilizados de acuerdo a cuatro razones distintas identificadas en el lugar de trabajo. La muestra estuvo compuesta por 463 profesionales que trabajan en la línea de producción del sector de la automoción. Para asegurar la validez y fiabilidad de las medidas, se utilizó el análisis factorial confirmatorio, y, más tarde, los resultados en las comparaciones de la utilización de cada estrategia de aprendizaje para cada finalidade se realizaron (Kruskal-Wallis y Wilcoxon) análisis de los factores. Los resultados mostraron que las estrategias utilizadas no son diferentes de acuerdo com las cuatro razones pesquisadas. Entre las estrategias estudiadas, la más utilizada es la ayuda interpersonal y son menos utilizados las consultas a material escrito y la participación en cursos ofrecidos por la empresa.

Palabras clave: Aprendizaje individual; Aprendizaje informal; Estrategias de aprendizaje.

REAd | Porto Alegre - Edição 83 - N 1 - Janeiro/Abril 2016 - p. 166-192 


\section{ESTRATÉGIAS DE APRENDIZAGEM EM FUNÇÃO DA FINALIDADE PARA O \\ APRENDIZADO: UM ESTUDO COM TRABALHADORES DA LINHA DE PRODUÇÃO DE UMA EMPRESA DO RAMO AUTOMOTIVO}

\section{INTRODUÇÃO}

Em geral, organizações dedicam maior atenção e recursos aos mecanismos formais de aprendizagem, constituídos por cursos de qualificação, treinamentos, programas corporativos de desenvolvimento, entre outros. Entretanto, essa prática não faz parte da rotina de todas as empresas, havendo também aquelas nas quais os indivíduos recebem apenas informações básicas e estritamente necessárias. Neste caso, muito do que se deve aprender ocorre durante a própria execução das atividades, caracterizando o predomínio da informalidade no processo de aprendizagem.

O processo de aprendizagem em si envolve fluxo de informações, comunicação corporativa, relações com clientes, gestão do conhecimento, treinamento, leiaute de planta, encontros informativos, entre outras possibilidades. Enfim, é improvável que uma única área centralize a organização de todas essas atividades e dedique uma atenção direcionada ao processo informal de aprendizagem dos empregados.

Tanto os meios formais quanto os informais devem servir a uma necessidade que o indivíduo possua. Nesta pesquisa serão consideradas situações nas quais há a intenção de se aprender, ou seja, houve a identificação dos motivos para os quais a aprendizagem está sendo desenvolvida e caracteriza-se como intencional. Tais motivos podem estar diretamente relacionados às tarefas e obrigações profissionais do indivíduo, fazendo com que este aprenda a fim de executar uma nova tarefa ou para resolver um problema (CAMILLIS; ANTONELLO, 2010). O indivíduo pode também interessar-se por aprender algo em função de perspectivas futuras que o aprendizado pode lhe proporcionar, como uma promoção ou a chance de trabalhar em outra área ou função.

Tomando como base as finalidades para as quais os indivíduos aprendem e quais suas estratégias de aprendizagem utilizadas (formais e informais), este trabalho propõe um modelo conceitual apresentado na Figura 1. Apesar de parecer óbvio e um tanto quanto "bom senso", que as pessoas utilizem estratégias de aprendizagem diferentes, dependendo do que elas pretendem fazer com este aprendizado (finalidades), os autores não identificaram pesquisa similar nas bases nacionais (ANPAD, SPELL, SCIELO) e internacionais (Portal CAPES, Proquest, Ebsco). Assim, esta pesquisa tem por objetivo identificar quais estratégias de aprendizagem são mais utilizadas em função de quatro finalidades distintas.

As contribuições esperadas ao se atingir esse objetivo são as seguintes:

- metodológica: mensurar as estratégias de aprendizagem (formais e informais);

REAd | Porto Alegre - Edição 83 - N 1 - Janeiro/Abril 2016 - p. 166-192 


\section{Eduardo Jardim Ushiro \& Diógenes de Souza Bido}

- teórica: classificar as estratégias de aprendizagem de acordo com seu uso para cada finalidade;

- prática: reconhecer a importância da aprendizagem que ocorre por meios informais no ambiente de trabalho, dependendo da finalidade que se busca para o aprendizado.

\section{Finalidade com que se busca a aprendizagem: \\ - Para resolver um problema no meu trabalho \\ - Quanto tenho de executar uma nova tarefa \\ - Para aumentar as minhas chances de crescimento na empresa \\ - Para obter autonomia e não depender dos outros \\ Elaborado pelos autores a partir de Camillis e Antonello (2010).}

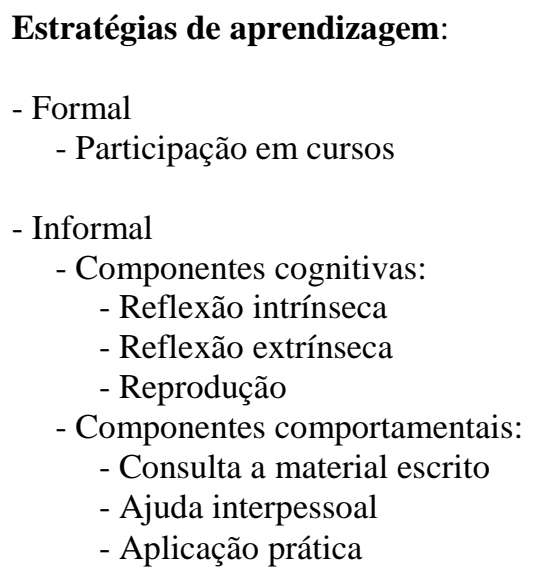

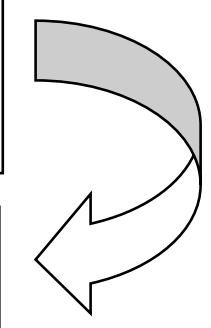

Para cada finalidade, quais estratégias de aprendizagem são mais usadas?

Figura 1 - Modelo conceitual

Fonte: Elaborado pelos autores a partir de Warr e Downing (2000), Holman et al. (2001), Cross (2007), Kock e Elsström (2010), Dirani (2011), Pantoja (2004), Brandão e Borges-Andrade (2009) e Conte (2011).

Para se atingir este objetivo, foi utilizada uma amostra de 463 trabalhadores da linha de produção de uma indústria do ramo automotivo. Essa amostra foi estratificada por finalidade da aprendizagem, da seguinte forma: 115 - resolver um problema, 115 - executar uma nova tarefa, 114 - obter autonomia, 119 - aumentar as chances de crescimento na empresa. A análise fatorial confirmatória foi utilizada para garantir que os itens utilizados para mensurar cada construto fossem válidos e confiáveis. Os escores fatoriais foram utilizados nos testes não paramétricos para se identificar quais estratégias são mais usadas para cada finalidade.

Além desta introdução, o artigo é composto pelo referencial teórico, metodologia, resultados e as considerações finais. 


\section{ESTRATÉGIAS DE APRENDIZAGEM EM FUNÇÃO DA FINALIDADE PARA O \\ APRENDIZADO: UM ESTUDO COM TRABALHADORES DA LINHA DE PRODUÇÃO DE UMA EMPRESA DO RAMO AUTOMOTIVO}

\section{REFERENCIAL TEÓRICO}

O referencial teórico desta pesquisa leva em conta: (i) aprendizagem nas organizações; (ii) aprendizagem de adultos; (iii) aprendizagem no local de trabalho; (iv) motivos para as quais os indivíduos aprendem (finalidades); (v) aprendizagem formal; (vi) aprendizagem informal e (vii) estratégias de aprendizagem.

\subsection{Aprendizagem nas organizações}

Os estudos acerca da aprendizagem nas organizações têm aumentado nos últimos anos, especialmente aqueles relacionados com teorias e ferramentas que proporcionam meios para uma maior eficiência das pessoas ou dos processos, assim como para a gestão do conhecimento adquirido pelos indivíduos em suas rotinas profissionais.

Dentre as teorias mais comumente estudadas, encontra-se a teoria da aprendizagem social, a qual concebe a aprendizagem como um processo que ocorre por meio das relações sociais entre os indivíduos, correlacionando o saber, o ser e o tornar-se. Esta linha teórica leva o processo de aprendizagem da mente do indivíduo e da educação formal para a vida diária na organização, compreendendo que o processo ocorre por meio da participação em processos sociais ou em comunidades de prática.

Sendo assim, a aprendizagem não estaria associada a uma atividade específica, limitada e intencional. Preferencialmente, a aprendizagem estaria ligada às atividades do ser humano, portanto, enquadra-se em algo que não se pode evitar. Perante essa perspectiva, pode-se afirmar que a teoria da aprendizagem social engloba tanto os aspectos epistemológicos quanto ontológicos, ou seja, considera o desenvolvimento do indivíduo como ser humano e o fato de que este se descobre com parte do seu mundo e da sua história. Não há, portanto, conforme a teoria da aprendizagem social, a possibilidade de considerar o desenvolvimento e a aprendizagem como processos separáveis (ELKJAER, 2004).

A teoria da aprendizagem individual considera a mente como o local onde a aprendizagem acontece, e como consequência, separa o contexto do indivíduo que aprende. A aprendizagem individual tem como foco a forma como as pessoas passam a conhecer algo e não como o contexto organizacional funciona como um elemento chave para a aprendizagem, socialização e desenvolvimento dos membros da organização.

REAd | Porto Alegre - Edição 83 - N 1 - Janeiro/Abril 2016 - p. 166-192 


\section{Eduardo Jardim Ushiro \& Diógenes de Souza Bido}

\subsection{Aprendizagem de adultos}

O interesse no aprendizado de adultos tem tomado a atenção de estudiosos desde os anos vinte, entretanto, somente nas últimas décadas é que o tema passou a ser pesquisado sistematicamente (MERRIAM, 2001). A questão que moldou muitos dos estudos iniciais foi sobre a capacidade dos adultos em aprender ou não. Esse foco levou os pesquisadores a testarem condições de tempo e memorização. A partir dos anos cinquenta, outros aspectos passaram a ser estudados e relacionados, como solução de problemas e desenvolvimento cognitivo.

Segundo Merriam (2001), como parte do movimento para diferenciar a educação de adultos de outras formas, educadores passaram a se questionar se o aprendizado de adultos poderia ser distinguido do aprendizado de crianças. Assim, emergiu o foco do que seria diferente entre um grupo e o outro. Knowles et al. (2005, p.61) define andragogia como "a arte e a ciência de ajudar adultos a aprender". O termo andragogia significa, em si, “aprendizagem de adultos", tendo Knowles como um dos principais expoentes neste campo.

Educação e aprendizagem são termos diferenciados por Knowles et al. (2005, p.10), de modo que, educação refere-se às "atividades realizadas ou iniciadas por um ou mais agentes destinados a resultar em mudanças no conhecimento, habilidades ou atitudes de um indivíduo, grupo ou comunidade". Já o termo aprendizagem, refere-se "à pessoa na qual tais mudanças ocorrem ou são esperadas que ocorram" (KNOWLES et al., 2005, p.10).

\subsection{Aprendizagem no local de trabalho}

Os estudos sobre a aprendizagem no local de trabalho abordam de forma abrangente a vida profissional do indivíduo, portanto, configuram-se como um termo amplo e aberto às diversas formas de aprendizado que possam ser vivenciadas.

A aprendizagem não ocorre somente em um local fixo no qual o indivíduo trabalha, mas também em outros pontos adjacentes como cursos, interações sociais, contato com clientes, fornecedores, sindicatos e em outros contextos relacionados ao trabalho. Frente à amplitude do campo, Illeris (2004) propõe um modelo holístico com elementos centrais, campos e processos que configuram a aprendizagem no trabalho. Segundo o autor, o aprendizado ocorre no encontro entre os ambientes de aprendizagem e os processos de aprendizagem dos empregados.

REAd | Porto Alegre - Edição 83 - N 1 - Janeiro/Abril 2016 - p. 166-192 


\section{ESTRATÉGIAS DE APRENDIZAGEM EM FUNÇÃO DA FINALIDADE PARA O APRENDIZADO: UM ESTUDO COM TRABALHADORES DA LINHA DE PRODUÇÃO DE UMA EMPRESA DO RAMO AUTOMOTIVO}

Três componentes são destacados no modelo: o ambiente de aprendizagem técnicoorganizacional, o ambiente de aprendizagem social e os processos de trabalho. Esses componentes estão em constante interação entre si, sendo que, entre os campos técnicoorganizacional e social, há uma região chamada pelo autor como "Prática de Trabalho", na qual a aprendizagem acontece. Isso significa que, qualquer aprendizado que acontece no trabalho, está direta ou indiretamente influenciado pela forma como a vida profissional é organizada, e como esta funciona na sociedade.

O modelo holístico de Illeris (2004) destaca também a forma pela qual o processo de interação social do indivíduo desenvolve um fluxo contínuo, impulsionando a aprendizagem por meio de opiniões, explicações, padrões de comportamento, percepções e impressões recebidas nas mais variadas formas. É exatamente na justaposição entre a "Identidade do Trabalho" e a "Prática de Trabalho" que se encontram os fatores mais importantes para o aprendizado na vida.

A importância da aprendizagem no local de trabalho não se limita ao indivíduo, contanto que, Kock e Ellström (2010) destacam que o tema é de grande interesse não só para os empregados, mas também para empregadores. O ambiente de trabalho constrói uma conexão com o desenvolvimento do indivíduo e da empresa. Dessa forma, passa a não haver mais distinção entre o horário de trabalho do empregado e seu horário de aprendizagem. A aprendizagem passa a ser baseada na experiência e os indivíduos podem aplicar seus conhecimentos diretamente, atribuindo mais sentido à vivência do processo. Kock e Ellström (2010) apontam o forte interesse que existe, atualmente, no local de trabalho como um espaço para educação e treinamento.

O aprendizado que ocorre no local de trabalho é visto como fator chave para questões de produtividade, inovação e competitividade. $\mathrm{O}$ autor salienta que o ambiente de aprendizagem que se constrói em uma organização não somente afeta o nível de aprendizagem em certas dimensões, mas também a própria qualidade da aprendizagem.

\subsection{Motivos para os quais os indivíduos aprendem (finalidades)}

Mediante pesquisa efetuada por Camillis e Antonello (2010), as autoras apontaram quatro motivos para os quais os indivíduos aprendem, sendo que, três deles serão utilizados nesta pesquisa: para resolver um problema, para executar uma tarefa e para obter autonomia.

REAd | Porto Alegre - Edição 83 - N 1 - Janeiro/Abril 2016 - p. 166-192 


\section{Eduardo Jardim Ushiro \& Diógenes de Souza Bido}

Neste trabalho, os motivos serão chamados de "finalidades", a fim de facilitar a explicação do modelo proposto, sem que o conceito seja alterado.

A primeira finalidade descrita por Camillis e Antonello (2010), refere-se à execução de uma nova tarefa. Mesmo a mais básica tarefa a ser realizada, exige que alguma orientação, procedimento ou regra sejam apresentados, portanto, remete à necessidade de serem aprendidos.

A segunda finalidade é a resolução de problemas. As autoras destacam que, em muitos casos, houve a necessidade de se aprender algo, seja a aquisição de um novo conhecimento ou o desenvolvimento de uma competência, para então se conseguir a solução desejada. Dependendo do problema a ser resolvido e das condições disponíveis, o indivíduo ou grupo poderão arriscar-se a experimentar alternativas desconhecidas, às vezes nunca antes testadas.

A terceira finalidade refere-se à necessidade de se obter autonomia e não precisar depender de outras pessoas no ambiente de trabalho. Busca-se, para esse fim, aprender a executar com maestria as tarefas, conhecendo leis, regras e procedimentos.

A quarta finalidade "Para aumentar minhas chances de crescimento na empresa", foi incluída neste trabalho conforme identificação pelos autores de que indivíduos procuram medidas formais de aprendizagem como parte de uma estratégia de médio ou longo prazo para construção de carreira.

\subsection{Aprendizagem formal}

A aprendizagem formal é a sétima estratégia pesquisada e aquela que, tradicionalmente, as organizações mais dedicam tempo e recursos financeiros, portanto, o resultado obtido na pesquisa poderá oferecer insumos que influenciem a empresa pesquisada na tomada de decisão sobre seu plano estratégico voltado aos meios formais de aprendizagem.

Os métodos formais de ensino e capacitação, como cursos, palestras e workshops representam a principal ferramenta estruturada pelas organizações com relação ao campo de aprendizagem dos indivíduos. Entretanto, partindo do princípio de que muitas competências e habilidade são desenvolvidas no próprio local de trabalho, e sem que nenhuma estrutura formal seja previamente, pode-se prever que iniciativas voltadas para a aprendizagem formal e informal complementem-se de forma equilibrada e eficiente. 


\section{ESTRATÉGIAS DE APRENDIZAGEM EM FUNÇÃO DA FINALIDADE PARA O APRENDIZADO: UM ESTUDO COM TRABALHADORES DA LINHA DE PRODUÇÃO DE UMA EMPRESA DO RAMO AUTOMOTIVO}

Em uma comparação entre meios formais e informais de aprendizagem, Cross (2007) atribui certo grau de passividade ao papel vivenciado por indivíduos em meios formais de aprendizagem e educação. Em contrapartida, meios informais estariam associados à atuação ativa, cabendo ao indivíduo a atuação e co-criação dos seus meios para aprender. Dirani (2011) destaca que os investimentos em Treinamento e Desenvolvimento (T\&D) são associados pelos empregados de uma organização a um pacote de benefícios.

Kock e Ellström (2010) definem aprendizagem formal como aquela que é planejada, organizada, na maioria das vezes financiada pelo empregador e que ocorre durante o horário de trabalho do empregado. Os autores ressaltam a distinção entre aprendizagem formal e informal como por aquisição e participação, respectivamente. Sob a perspectiva formal ou por aquisição, a aprendizagem é vista como um resultado observável, frequentemente acompanhado por um certificado ou com graduação em um curso ou programa estruturado conforme a orientação de outras pessoas. Na perspectiva informal, a aprendizagem é um processo no qual as pessoas melhoram seu desempenho realizando atividades por meio da interação com outras pessoas, ferramentas, matérias, entre outros, de modo que, o aprendizado surge naturalmente como parte do processo.

\subsection{Aprendizagem informal}

Aramo-Immonen et al. (2011) argumentam que a aprendizagem informal consiste em tudo que está relacionado diretamente com o processo de trabalho, incluindo sua própria execução. Em todos os níveis e setores nos quais o trabalho é executado, novidades que afetam o processo são aprendidas de uma forma ou outra, direta ou indiretamente. Os aprendizados informais são comumente não registrados ou mesmo percebidos, portanto, podese considera-los como conhecimento tácito ou acúmulo de know-how. Ambos, tanto o conhecimento tácito, quanto o acúmulo de know-how, possuem significado essencial para o desenvolvimento da identidade profissional, formando assim, parte de uma qualificação que não pode ser ensinada (MARSICK; WATKINS, 2001).

Leslie et al. (1998) apontam que, cada vez mais, o ambiente organizacional requer indivíduos que estão constantemente crescendo, motivados, aplicados e capazes de trabalhar de forma colaborativa. Embora as organizações possuam meios de estimular os processos de aprendizagem informal e reconheçam seus benefícios, a maioria dos indivíduos ainda associa a proposta de uma iniciativa para a aprendizagem com modelos estruturados de ensino. A 


\section{Eduardo Jardim Ushiro \& Diógenes de Souza Bido}

expectativa de desenvolvimento de habilidades e competências ainda está fortemente vinculada com medidas planejadas formalmente pela organização. Conforme afirma Conlon (2003), esse vínculo pode provocar um sentimento de desamparo ou falta de direcionamento nos empregados, especialmente se forem novos no quadro organizacional.

Para Coelho Jr. e Mourão (2011), a ocorrência do suporte à aprendizagem antecede a aplicação do aprendido. As fases iniciais do processo de aprendizagem requerem uma atitude mais favorável por parte de colegas e chefias quanto ao esclarecimento de dúvidas e ao incentivo à autonomia e pró-atividade do aprendiz. As fases terminais do ato de aprender são mais objetivas quanto ao impacto da aprendizagem no desempenho e exercem efeitos diretos nos resultados de trabalho do indivíduo.

Uma classificação mais acurada do conceito de suporte à aprendizagem e de suas etapas sugere que é preciso identificar empiricamente o que é essencial em suas formas, aspectos e funções, explicando seus efeitos, ciclos de ascensão e declínio, e, ainda, sua eficácia. Em outras palavras, se o indivíduo perceber que seus chefes e colegas apoiam a aplicação de novas aprendizagens no trabalho, ele poderá entender que tal aplicação é vantajosa e passar a ser mais proativo em comportamentos de transferência de aprendizagem. (COELHO JR.; MOURÃO, 2011).

A sociologia tem oferecido importantes contribuições para o estudo da aprendizagem informal no ambiente de trabalho. Como parte do contexto cunhado por esta área do conhecimento, pode-se citar os termos "participação" e "reflexividade".

$\mathrm{O}$ conceito de reflexividade está intimamente ligado à participação, pois acontece justamente, quando o fluxo da experiência é interrompido e o sujeito reflete sobre o processo e seu conhecimento. Uma das consequências provenientes da reflexividade, é que o conhecimento tácito emerge e passa a ser objeto de reflexão e útil para solucionar a interrupção em questão.

É por meio de manifestações e interações não estruturadas, como a troca rotineira de informações, participação conjunta em projetos, entre outras, que a aprendizagem pela prática configura-se como uma fonte inevitável no processo de qualificação e desenvolvimento dos indivíduos nas organizações.

\subsection{Estratégias de aprendizagem informal no local de trabalho}

Estratégias de aprendizagem podem ser definidas como práticas que as pessoas utilizam para a aquisição e desenvolvimento de conhecimento em qualquer contexto 


\section{ESTRATÉGIAS DE APRENDIZAGEM EM FUNÇÃO DA FINALIDADE PARA O APRENDIZADO: UM ESTUDO COM TRABALHADORES DA LINHA DE PRODUÇÃO DE UMA EMPRESA DO RAMO AUTOMOTIVO}

(KARDASH et al., 1991 apud HOLMAN et al., 2001). Alguns estudos sobre estratégias de aprendizagem foram realizados nos últimos anos com o objetivo de identificar quais são as mais utilizadas conforme públicos distintos.

As estratégias consideradas como cognitivas foram divididas pelos autores em três tipos: reprodução, organização e elaboração, as quais, respectivamente, representam procedimentos executados por meio da repetição contínua sem reflexão, procedimentos que criam estruturam mentais e inter-relacionam elementos para a aprendizagem e procedimentos que fazem conexões mentais entre o conteúdo a ser aprendido e o conhecimento já existente.

Já as estratégias comportamentais foram divididas em busca por ajuda interpessoal, busca por ajuda em material escrito e aplicação prática. As estratégias auto regulatórias são: controle emocional, controle da motivação e monitoramento da compreensão.

A partir das nove estratégias sugeridas por Warr e Allan (1998 apud WARR; DOWNING, 2000), Warr e Downing (2000) construíram um questionário com 45 itens que foi aplicado em duas amostras, sendo uma composta por estudantes universitários e outras por participantes de um curso profissionalizante para técnicos veiculares.

A partir das conclusões de Warr e Downing (2000), Holman et al. (2001) aplicaram um instrumento de pesquisa a 628 empregados de um call center sugerindo seis fatores de aprendizagem entre as estratégias de caráter cognitiva e comportamental. São elas: Reprodução, Reflexão intrínseca, Reflexão extrínseca, Busca de ajuda em material escrito, Busca de ajuda interpessoal e Aplicação prática.

Com base nos trabalhos de Warr e Downing (2000) e Holman et al. (2001), Pantoja (2004) elaborou um estudo com profissionais de diferentes ocupações presentes na Classificação Brasileira de Ocupações (CBO). A classificação Reflexão ativa foi substituída por Reflexão intrínseca e Reflexão extrínseca, incorporando, assim, os resultados da pesquisa de Holman et al. (2001). Conte (2011) realizou um estudo com base nas mesmas estratégias de aprendizagem propostas por Holman et al. (2001), entretanto, com profissionais da área de enfermagem.

Brandão e Borges-Andrade (2009) desenvolveram uma pesquisa com gestores do setor bancário utilizando as mesmas classificações e estratégias dos trabalhos anteriores (Quadro 1). Em relação aos resultados de Pantoja (2004), Brandão e Borges-Andrade (2009) identificaram uma pequena melhoria na consistência de certos fatores, como Busca por ajuda 


\section{Eduardo Jardim Ushiro \& Diógenes de Souza Bido}

interpessoal, por exemplo, e uma leve piora em outros, como Reprodução e Busca de ajuda em material escrito.

Brandão e Borges-Andrade (2009) consideraram que o principal aprimoramento efetuado na escala diz respeito à substituição de itens da estratégia Reprodução, os quais, não representariam adequadamente a ideia do que significa aprender por meio da reprodução mental de informações. Afirmam os autores que, os conteúdos oriundos da escala de Holman et al. (2001) e aplicados anteriormente por Pantoja (2004) não descrevem esforços ativos do indivíduo para a aprendizagem, indicando certa alienação ou deficiência em seu desempenho.

No presente estudo, em função de haver quatro finalidades distintas para as quais estão associadas sete estratégias de aprendizagem (seis estratégias informais e uma estratégia formal), os itens aplicados por Conte (2011) tiveram de ser adaptados, de modo que, cada item iniciar-se-á com a finalidade do aprendizado e terá sua continuidade com cada um dos 36 itens referentes às sete estratégias pesquisadas.

Quadro 1 - Estratégias de aprendizagem e conceitos

\begin{tabular}{|l|l|l|}
\hline \multicolumn{2}{|c|}{ Estratégias } & \multicolumn{1}{c|}{ Definição } \\
\hline \multirow{3}{*}{ Cognitivas } & Reprodução & $\begin{array}{l}\text { Repetição mental da informação, sem reflexão sobre } \\
\text { seu significado. }\end{array}$ \\
\cline { 2 - 3 } & Reflexão extrínseca & $\begin{array}{l}\text { Reflexão sobre relações entre o trabalho e diferentes } \\
\text { aspectos da organização. }\end{array}$ \\
\cline { 2 - 3 } & Reflexão intrínseca & $\begin{array}{l}\text { Reflexão sobre relações entre partes componentes } \\
\text { do trabalho. }\end{array}$ \\
\hline \multirow{4}{*}{ Comportamentais } & Busca por ajuda interpessoal & Busca ativa do auxílio de outras pessoas. \\
\cline { 2 - 3 } & Busca por ajuda em material escrito & $\begin{array}{l}\text { Pesquisa e localização de informações em } \\
\text { documentos, manuais, livros e outras fontes não- } \\
\text { sociais. }\end{array}$ \\
\cline { 2 - 3 } & Aplicação prática & $\begin{array}{l}\text { Experimentação, tentativa de colocar em prática os } \\
\text { próprios conhecimentos enquanto aprende. }\end{array}$ \\
\hline
\end{tabular}

Fonte: Adaptado pelos autores a partir de Brandão e Borges-Andrade (2009, p. 4).

\section{METODOLOGIA}

A metodologia utilizada neste estudo foi de caráter quantitativo e seus detalhes sobre a coleta e análise dos dados, assim como as características da organização e dos participantes serão apresentadas ao longo desse capítulo. 


\section{ESTRATÉGIAS DE APRENDIZAGEM EM FUNÇÃO DA FINALIDADE PARA O \\ APRENDIZADO: UM ESTUDO COM TRABALHADORES DA LINHA DE PRODUÇÃO DE UMA EMPRESA DO RAMO AUTOMOTIVO}

\subsection{Características da Organização Pesquisada}

A empresa pesquisada é uma multinacional do ramo automotivo localizada no estado de São Paulo e está presente há mais de cinco décadas no mercado brasileiro como uma das marcas líderes em vendas. Os produtos e a própria tradição da empresa são reconhecidos mundialmente pelo alto padrão em qualidade e inovação tecnológica. Uma prova disso é a detenção de mais de 4.000 patentes no respectivo ramo.

A empresa conta com cerca de 12.000 empregados, sendo que, aproximadamente 7.000 possuem suas atividades ligadas ao processo produtivo. Esta quantidade pode ser considerada elevada se comparada com outras empresas do mesmo setor. O motivo principal para esta porcentagem refere-se ao sistema de produção caracterizado por processos manuais, artesanais, internos e amplamente padronizados, contrapondo outras empresas que trabalham de forma mais automatizada, robotizada ou com um quadro elevado de terceiros na linha de produção dos veículos.

Essas características reforçam a necessidade da empresa de desenvolver e qualificar continuamente seus empregados em diversos campos relacionados ao processo produtivo e a outros temas correlatos, como a cadeia de abastecimento da produção e a área de manutenção de máquinas e sistemas. O foco em processos executados por pessoas, e não por máquinas, implica em uma demanda maior e mais diversificada no aprendizado de procedimentos, operações, legislações, medidas de segurança, normas regulamentadoras, etc.

A maior parte das atividades executadas oferece risco de acidentes pelo manuseio de máquinas, ferramentas, peças metálicas pesadas, contato com rede elétrica, movimentação de cargas e operação de veículos industriais como paleteiras, rebocadores e empilhadeiras. Além disso, o acesso produtos químicos como fluidos e óleos demandam a utilização de equipamentos de proteção individual (EPI’s) e procedimentos cuidadosos e para se evitar contaminações ao meio ambiente.

O período em que a pesquisa foi realizada foi marcado por uma forte retração do mercado, levando a empresa à adoção de iniciativas focadas em redução de custos fixos como a abertura de programa de demissão voluntária e o corte da verba anual destinada a programas de qualificação e treinamento.

REAd | Porto Alegre - Edição 83 - № 1 - Janeiro/Abril 2016 - p. 166-192 


\section{Eduardo Jardim Ushiro \& Diógenes de Souza Bido}

\subsection{Participantes da Pesquisa}

Participaram trabalhadores que atuam diretamente na linha de produção e outros que atuam em áreas de apoio como logística, por exemplo. Os cargos dos empregados são os seguintes: operador de produção, operador de logística, montador; revisor de veículos; operador de comando numérico computadorizado (CNC); operador célula usinagem; conferente; operador dinamômetro e ferramenteiro.

O ambiente físico de trabalho no qual estes profissionais atuam caracteriza-se por alto nível de ruído (exigência do uso de protetores auriculares), baixa luminosidade, exposição ao sol em alguns casos e contato constante com impurezas provenientes de peças, ferramentas e produtos químicos como óleos, graxas e solventes.

Apesar da amostra não ser aleatória (participou quem quis), a coleta de dados procurou manter os grupos (por finalidade) os mais homogêneos possíveis quanto às características demográficas, o que é confirmado pelos seguintes resultados:

- Idade por finalidade (teste de Kruskal-Wallis com $\mathrm{p}=0,415$ )

- Tempo de empresa por finalidade (teste de Kruskal-Wallis com p = 0,699)

- Gênero por finalidade (teste de qui-quadrado com $\mathrm{p}=0,128$ )

- Escolaridade por finalidade (teste de qui-quadrado com $p=0,883$ )

Além disso, o perfil apresentado na Tabela 1 é bem típico do que se observa na linha de produção, grosso modo: homens com uma década de empresa.

Tabela 1 - Variáveis demográficas

\begin{tabular}{|c|c|c|c|c|c|}
\hline & Min-Máx & Média (d.p.) & Escolaridade & $\mathbf{n}$ & $\%$ \\
\hline Idade (anos) & 18 a 54 & $36,2(7,99)$ & $1^{\circ}$ Grau completo & 17 & 3,7 \\
\hline \multirow[t]{2}{*}{ Tempo de empresa (anos) } & 1 a 36 & $11,0(7,34)$ & $2^{\circ}$ Grau completo & 218 & 47,1 \\
\hline & & & Técnico completo & 67 & 14,5 \\
\hline Gênero & $\mathbf{n}$ & $\%$ & Superior completo & 146 & 31,5 \\
\hline Masculino & 436 & 94,2 & Pós-graduação & 15 & 3,2 \\
\hline Feminino & 27 & 5,8 & Total & 463 & 100 \\
\hline
\end{tabular}

Fonte: Resultados da pesquisa.

\subsection{Instrumento de coleta de dados}

O instrumento utilizado nesta pesquisa teve como base o questionário aplicado por Conte (2011). Para a formulação do novo instrumento de pesquisa, todos os itens foram REAd | Porto Alegre - Edição 83 - N 1 - Janeiro/Abril 2016 - p. 166-192 


\section{ESTRATÉGIAS DE APRENDIZAGEM EM FUNÇÃO DA FINALIDADE PARA O APRENDIZADO: UM ESTUDO COM TRABALHADORES DA LINHA DE PRODUÇÃO DE UMA EMPRESA DO RAMO AUTOMOTIVO}

reescritos de modo que cada um representasse uma extensão da finalidade apresentada. Uma segunda adaptação para esta pesquisa foi a supressão de algumas palavras dos itens absorvidos do questionário aplicado por Conte (2011). Esta ação foi necessária em alguns casos devido à existência das mesmas palavras na própria finalidade apresentada. Em outros casos, por uma questão de simplificação do item, para que este não ficasse extenso demais, já que a questão tem seu início na finalidade pesquisada e não no item em si.

Foram confeccionados quatro questionários distintos contendo os mesmos itens (mas ajustados à finalidade), entretanto cada um com uma finalidade diferente no cabeçalho, que serviu como orientação para que os respondentes pensassem nas estratégias utilizadas. Antes da coleta de dados foram realizados pré-testes com potenciais respondentes para avaliar a validade de face (redação, formato etc.) e os ajustes necessários foram feitos.

Os questionários estão disponíveis com o primeiro autor, e não foram incluídos aqui apenas por questão de espaço. No quadro 2 são apresentados os dois primeiros itens para cada estratégia de aprendizagem, o questionário completo contém 36 itens.

Quadro 2 - Amostra de itens do questionário

\begin{tabular}{|c|c|c|c|}
\hline \multicolumn{4}{|c|}{ Para resolver um problema que surge no meu trabalho, eu... } \\
\hline $\begin{array}{c}\text { Estratégia de } \\
\text { aprendizagem }\end{array}$ & $\begin{array}{c}\text { Ordem no } \\
\text { questionário }\end{array}$ & Rótulo & Assertiva \\
\hline \multirow{2}{*}{$\begin{array}{l}\text { Aprendizagem } \\
\text { formal } \\
\text { (4 itens) }\end{array}$} & 23 & FOR1 & $\begin{array}{l}\text { participo de treinamentos que aumentam meu conhecimento e } \\
\text { melhoram meu desempenho. }\end{array}$ \\
\hline & 36 & FOR2 & $\begin{array}{l}\text { busco programas que aumentem minha capacitação e } \\
\text { formação. }\end{array}$ \\
\hline \multirow{2}{*}{$\begin{array}{l}\text { Reflexão } \\
\text { intrínseca } \\
\text { (5 itens) }\end{array}$} & 7 & INT1 & $\begin{array}{l}\text { procuro compreender como novos conhecimentos e } \\
\text { habilidades podem ser integrados. }\end{array}$ \\
\hline & 16 & INT2 & $\begin{array}{l}\text { procuro compreender o máximo possível cada uma das partes } \\
\text { que compõem a solução do problema. }\end{array}$ \\
\hline \multirow{2}{*}{$\begin{array}{l}\text { Reflexão } \\
\text { extrínseca } \\
\text { (6 itens) }\end{array}$} & 15 & EXT1 & $\begin{array}{l}\text { relaciono a solução do problema com os valores da } \\
\text { organização. }\end{array}$ \\
\hline & 10 & EXT2 & $\begin{array}{l}\text { tento conhecer como o problema está relacionado com as } \\
\text { diferentes áreas da organização. }\end{array}$ \\
\hline \multirow{2}{*}{$\begin{array}{l}\text { Reprodução } \\
\text { (6 itens) }\end{array}$} & 9 & REP1 & $\begin{array}{l}\text { repito mentalmente informações e conhecimentos já } \\
\text { adquiridos }\end{array}$ \\
\hline & 12 & REP2 & utilizo instruções, normas e procedimentos que memorizei. \\
\hline \multirow{2}{*}{$\begin{array}{l}\text { Consulta a } \\
\text { material escrito } \\
\text { (6 itens) }\end{array}$} & 6 & MAT1 & $\begin{array}{l}\text { busco informações em desenhos de projeto, guias, manuais } \\
\text { entre outros. }\end{array}$ \\
\hline & 21 & MAT2 & leio instruções, artigos técnicos e/ou normas da empresa. \\
\hline \multirow{2}{*}{$\begin{array}{l}\text { Ajuda interpessoal } \\
\text { (4 itens) }\end{array}$} & 24 & AJU1 & $\begin{array}{l}\text { tiro dúvidas com colegas mais experientes e/ou especialistas } \\
\text { no assunto. }\end{array}$ \\
\hline & 34 & AJU2 & $\begin{array}{l}\text { busco trocar informações e conhecimentos com outras } \\
\text { pessoas. }\end{array}$ \\
\hline
\end{tabular}

REAd | Porto Alegre - Edição 83 - N 1 - Janeiro/Abril 2016 - p. 166-192 


\section{Eduardo Jardim Ushiro \& Diógenes de Souza Bido}

Aplicação prática (5 itens)

PRA1 $\quad$ testo novos conhecimentos aplicando-os na prática. PRA2 aplico novos conhecimentos e habilidades.

Fonte: Elaborado pelos autores a partir de Warr e Downing (2000), Holman et al. (2001), Cross (2007), Kock e Ellström (2010), Dirani (2011), Pantoja (2004), Brandão e Borges-Andrade (2009) e Conte (2011).

\subsection{Coleta de dados}

Por meio do software G*Power 3 (FAUL et al., 2007) foi estimada a amostra mínima em 338 casos para se atingir um poder estatístico de 0,8 , com um nível de significância de 0,05 e um tamanho do efeito médio Cohen (1988).

Para conseguir essa quantidade de respostas junto à linha de produção, o primeiro autor teve autorização da empresa para acessar os funcionários diretamente, mas em pequenos grupos para não prejudicar a produção, assim, ele teve a oportunidade de explicar o objetivo da pesquisa e esclareceu as dúvidas sobre o preenchimento do questionário.

Após a exclusão de um caso por excesso de dados faltantes e outro por excesso de respostas iguais para assertivas diferentes $-81 \%$ de respostas no topo da escala -, a amostra ficou com 463 casos distribuídos de modo uniforme entre as quatro finalidades.

\subsection{Análise dos dados}

Após a "limpeza" do banco de dados (análise de dados faltantes, dados atípicos, erros de digitação etc.), foi realizada uma análise descritiva para identificar o perfil dos respondentes e avaliar se os grupos eram homogêneos.

Em seguida foi utilizada a análise fatorial confirmatória (AFC) para se avaliar se os itens possuíam validade e confiabilidade, aqueles que apresentaram baixas cargas fatoriais (falta de validade convergente e confiabilidade) foram excluídos da escala, assim como os itens que possuíam alta carga cruzada, o que indica falta de validade discriminante (HAIR JR. et al., 2014).

Após rodar uma AFC para cada banco de dados (finalidade), foram calculados os escores fatoriais no SmartPLS 2.0.M3 (RINGLE; WENDE; WILL, 2005), que foram utilizados nos testes não-paramétricos para se identificar quais estratégias eram mais utilizadas em função da finalidade. 


\section{ESTRATÉGIAS DE APRENDIZAGEM EM FUNÇÃO DA FINALIDADE PARA O \\ APRENDIZADO: UM ESTUDO COM TRABALHADORES DA LINHA DE PRODUÇÃO DE UMA EMPRESA DO RAMO AUTOMOTIVO}

\section{RESULTADOS}

Os resultados serão apresentados em duas etapas, a primeira focando na AFC, para garantir que as escalas são válidas e confiáveis e a segunda com os testes não-paramétricos para se atender o objetivo da pesquisa.

\subsection{Avaliação do modelo de mensuração}

Para rodar a AFC no SmartPLS, a cada construto (ou variável latente - VL) foram atribuídos seus itens e entre os construtos foram incluídas setas estruturais de modo que todos estivessem conectados com todos (BROWN, 2006) e o esquema de ponderação para o algoritmo PLS (Partial Least Squares) foi o "factor" (HAIR JR. et al., 2014). A Figura 2 ilustra esta etapa da análise.

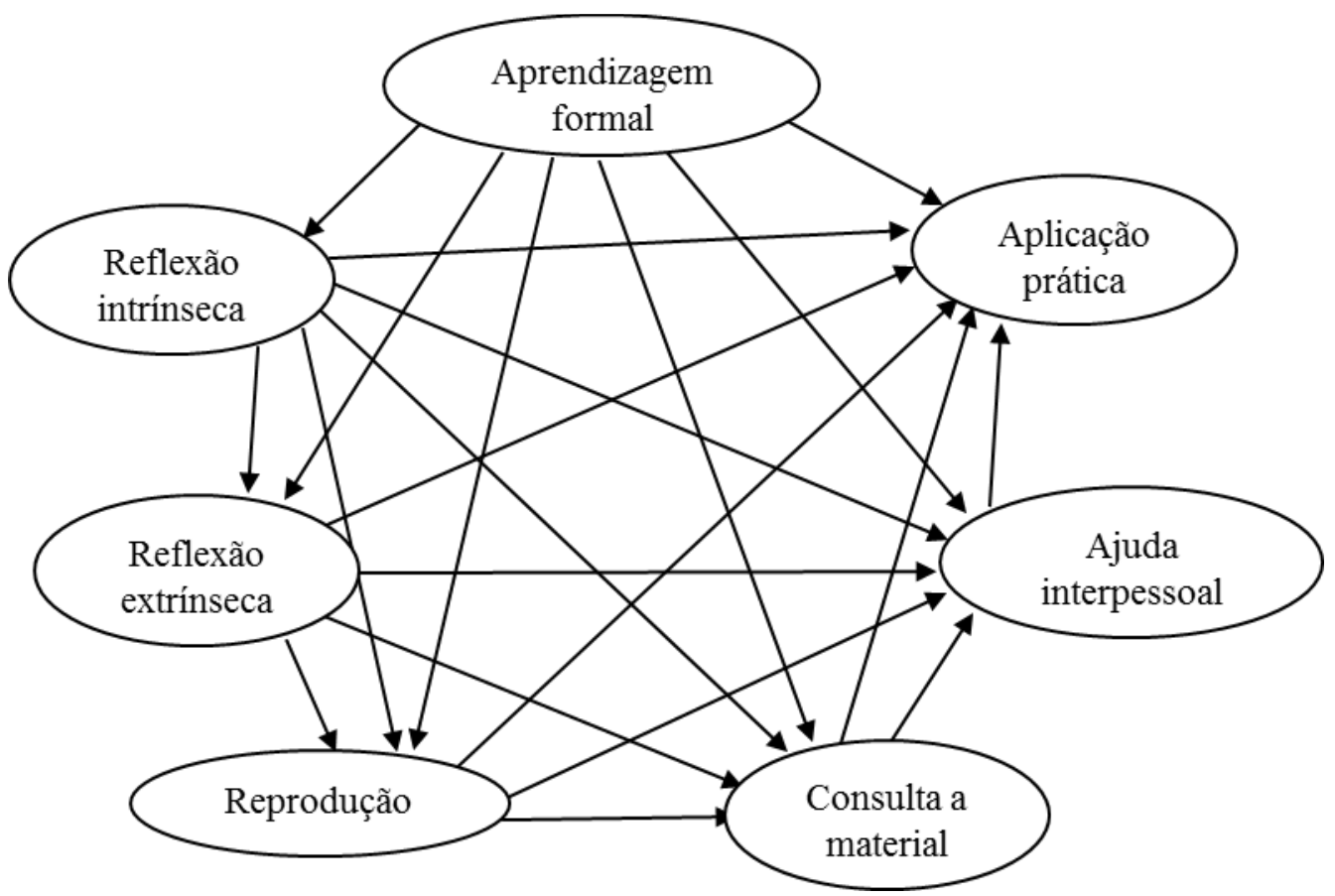

Figura 2 - Análise fatorial confirmatória

Fonte: Elaborado pelos autores

Nota: Não foram incluídos os itens (ou indicadores) para manter a figura simples, mas cada construto foi mensurado por quatro a seis itens. O Quadro 3 contém as quantidades de itens após a AFC.

Para cada banco de dados (4 finalidades) a AFC foi rodada três vezes (Quadro 3), até se obter resultados adequados para a validade e confiabilidade (HAIR JR. et al., 2014):

REAd | Porto Alegre - Edição 83 - N 1 - Janeiro/Abril 2016 - p. 166-192 


\section{Eduardo Jardim Ushiro \& Diógenes de Souza Bido}

- Validade convergente: variância média extraída (VME) maior que 0,5;

- Validade discriminante no nível dos itens: todos os itens com carga fatorial mais alta na sua variável latente (VL) do que em outras VL;

- Validade discriminante no nível dos construtos: as correlações entre os construtos são menores do que a raiz quadrada da VME;

- Confiabilidade composta maior que 0,7 .

Por um lado, a analise feita separadamente (4 bancos de dados, um para cada finalidade) teve o objetivo de garantir que em cada caso os resultados psicométricos (validade e confiabilidade) fossem os melhores possíveis, e por outro lado, pode haver a crítica de invariância do modelo de mensuração, ou seja, os indicadores que foram usados para mensurar o mesmo construto não foram exatamente os mesmos nos quatro casos. Por isso, posteriormente, foi realizada nova análise fatorial confirmatória, com os dados agregados ( $\mathrm{n}=$ 463), seguida de todas as comparações de médias, o que resultou nos mesmos valores que tinham sido obtidos com os modelos iniciais (diferenças inferiores a 0,2 em uma escala de 1 a 10). Assim, conclui-se que os modelos de mensuração são equivalentes (conteúdo e medição), apesar de não ter sido usado exatamente os mesmos indicadores em cada caso.

Quadro 3 - Itens eliminados a cada rodada da análise fatorial confirmatória

\begin{tabular}{|c|c|c|c|c|}
\hline & Resolver problema & $\begin{array}{c}\text { Executar nova } \\
\text { tarefa }\end{array}$ & Obter autonomia & $\begin{array}{c}\text { Aumentar chances } \\
\text { de crescimento }\end{array}$ \\
\hline Rodada 1 & $\begin{array}{l}\text { Com todos os itens } \\
\text { Aplicação prática e } \\
\text { reprodução com baixas } \\
\text { validade convergente e } \\
\text { confiabilidade }\end{array}$ & $\begin{array}{l}\text { Com todos os itens } \\
\text { Aplicação prática, } \\
\text { reprodução e reflexão } \\
\text { intrínseca com baixas } \\
\text { validade convergente } \\
\text { e confiabilidade }\end{array}$ & $\begin{array}{l}\text { Com todos os itens } \\
\text { Aplicação prática, } \\
\text { reprodução e ajuda } \\
\text { interpessoal com } \\
\text { baixas validade } \\
\text { convergente e } \\
\text { confiabilidade }\end{array}$ & $\begin{array}{l}\text { Com todos os itens } \\
\text { Reprodução com } \\
\text { baixas validade } \\
\text { convergente e } \\
\text { confiabilidade } \\
\text { Reflexão intrínseca e } \\
\text { extrínseca sem } \\
\text { validade } \\
\text { discriminante }\end{array}$ \\
\hline $\begin{array}{l}\text { Modelo } \\
\text { final }\end{array}$ & $\begin{array}{l}\text { Aprendizagem formal } \\
\text { (4 itens) } \\
\text { Reflexão intrínseca (4 } \\
\text { itens) } \\
\text { Reflexão extrínseca (6 } \\
\text { itens) } \\
\text { Reprodução (3 itens) } \\
\text { Consulta a material } \\
\text { escrito (6 itens) }\end{array}$ & $\begin{array}{l}\text { AF ( } 4 \text { itens }) \\
\text { RI (3 itens) } \\
\text { RE (5 itens) } \\
\text { R ( } 2 \text { itens }) \\
\text { CME (6 itens) } \\
\text { AI (3 itens) } \\
\text { AP (3 itens) }\end{array}$ & $\begin{array}{l}\text { AF (4 itens) } \\
\text { RI (4 itens) } \\
\text { RE (6 itens) } \\
\text { R ( } 3 \text { itens }) \\
\text { CME (6 itens) } \\
\text { AI (3 itens) } \\
\text { AP (4 itens) }\end{array}$ & $\begin{array}{l}\text { AF (4 itens) } \\
\text { RI (4 itens) } \\
\text { RE (4 itens) } \\
\text { R ( } 3 \text { itens }) \\
\text { CME (6 itens) } \\
\text { AI (4 itens) } \\
\text { AP (4 itens) }\end{array}$ \\
\hline
\end{tabular}

REAd | Porto Alegre - Edição 83 - N 1 - Janeiro/Abril 2016 - p. 166-192 
ESTRATÉGIAS DE APRENDIZAGEM EM FUNÇÃO DA FINALIDADE PARA O

APRENDIZADO: UM ESTUDO COM TRABALHADORES DA LINHA DE PRODUÇÃO DE UMA EMPRESA DO RAMO AUTOMOTIVO

\begin{tabular}{|l|l|l|l|l|}
\hline Ajuda interpessoal (3 & & & \\
itens) & & & \\
Aplicação prática (4 & & & \\
itens) & & & \\
\hline
\end{tabular}

Fonte: Resultados da pesquisa.

Nota 1: Atendeu todos os critérios de validade e confiabilidade.

Nota 2: Resultados similares aos anteriores com exceção da validade discriminante entre a reflexão extrínseca e intrínseca, que apresentaram correlação de 0,76 (superior à raiz quadrada da VME da reflexão intrínseca).

Nota 3: Os resultados detalhados da AFC (cargas fatoriais, correlações entre os construtos etc.) estão disponíveis com o primeiro autor, só não foram incluídos aqui por questão de espaço.

\subsection{Análise dos escores fatoriais}

Os escores fatoriais obtidos para cada estratégia de aprendizagem foram usados para se testar se havia diferença em função da finalidade do aprendizado. Na Figura 3 observa-se que os escores fatoriais da ajuda interpessoal se distribuem de modo assimétrico nas quatro finalidades (teste K-S com p < 0,05). Também se observam as linhas centrais (medianas) com pequenas diferenças entre elas, assim como as caixas ( $1^{\circ}$ e $3^{\circ}$ quartil).

Apesar da diferença das médias ser significante do ponto de vista estatístico (teste de Kruskal-Wallis com $\mathrm{p}=0,027$ ) observa-se pelo gráfico de barras, que essas diferenças são muito pequenas do ponto de vista empírico (menor média $=8,3$ e maior média $=8,7$; menor mediana $=8,6$ e maior mediana $=9,0$ ).

A ajuda interpessoal é muito utilizada, independente da finalidade (assumindo a interpretação do ponto de vista empírico), pois as médias e medianas são superiores a 8 em uma escala de 1 a 10 , onde 8 equivale a "faço muito". 


\section{Eduardo Jardim Ushiro \& Diógenes de Souza Bido}

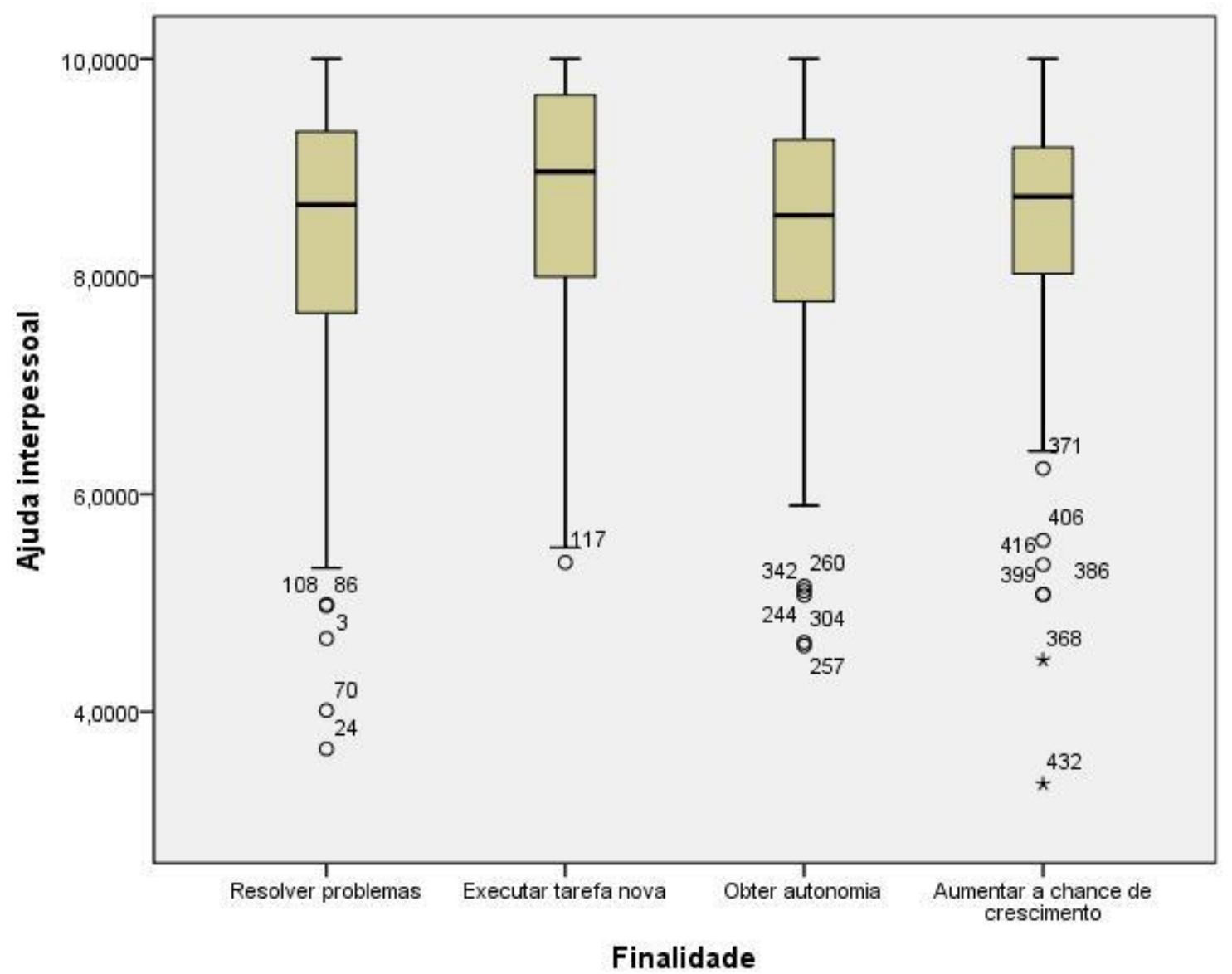

Figura 3 - Distribuição dos escores fatoriais em função da finalidade do aprendizado

Fonte: Resultados da pesquisa.

A ajuda interpessoal foi a estratégia de aprendizagem que apresentou maior diferença de escores em função dos fatores, para as demais estratégias não foram incluídos os gráficos porque são semelhantes ao da Figura 3, só que as diferenças entre os escores (boxplots) são menores ainda, na verdade, não foram significantes (teste de Kruskal-Wallis com p > 0,05).

Estes resultados nos aproximam do objetivo da pesquisa, porque neste ponto ficou claro que a estratégia de aprendizagem não depende da finalidade, o que é contra intuitivo, porque, apesar de não terem sido estabelecidas hipóteses a priori, o bom senso apontava no sentido de que a aprendizagem formal seria mais utilizada se a finalidade fosse aumentar a chance de crescimento. Em geral, as promoções nas organizações precisam ser justificadas por meio de avaliações de desempenho formais e pelo potencial que o candidato apresenta para futuras realizações. A aquisição de certificados e competências atestadas por meios formais representa uma forma de demonstrar o aumento da qualificação do respondente.

Para finalizar a análise e atender o objetivo da pesquisa foram realizados testes de Wilcoxon com correção de Bonferroni devido às múltiplas comparações, para identificar REAd | Porto Alegre - Edição 83 - N 1 - Janeiro/Abril 2016 - p. 166-192 


\section{ESTRATÉGIAS DE APRENDIZAGEM EM FUNÇÃO DA FINALIDADE PARA O APRENDIZADO: UM ESTUDO COM TRABALHADORES DA LINHA DE PRODUÇÃO DE UMA EMPRESA DO RAMO AUTOMOTIVO}

quais estratégias eram mais ou menos utilizadas. Os resultados foram sintetizados na Tabela 2 e na Figura 4.

Tabela 2 - Estatísticas descritivas dos escores fatoriais das estratégias de aprendizagem

\begin{tabular}{lccccc}
\hline \multicolumn{1}{c}{ Estratégia de aprendizagem } & Média & Mediana & $\begin{array}{c}\text { Desvio } \\
\text { padrão }\end{array}$ & $\begin{array}{c}\text { Coeficiente } \\
\text { de variação }\end{array}$ & Min-Máx. \\
\hline Ajuda interpessoal & 8,5 & 8,7 & 1,27 & $15 \%$ & 3,3 a 10 \\
Aplicação Prática & 8,0 & 8,2 & 1,42 & $18 \%$ & 2,3 a 10 \\
Reprodução & 8,0 & 8,1 & 1,40 & $18 \%$ & 2,1 a 10 \\
Reflexão intrínseca & 7,5 & 7,6 & 1,37 & $18 \%$ & 2,1 a 10 \\
Reflexão extrínseca & 6,7 & 7,0 & 1,60 & $24 \%$ & 1,9 a 10 \\
Consulta a material escrito & 6,2 & 6,4 & 1,91 & $31 \%$ & 1,0 a 10 \\
Aprendizagem formal & 6,2 & 6,3 & 2,00 & $32 \%$ & 1,0 a 10 \\
\hline
\end{tabular}

Fonte: Resultados da pesquisa.

Nota 1: Pelos testes de Wilcoxon ( $\mathrm{p}>0,05)$ não há diferença significante entre Aplicação prática e Reprodução, e entre Consulta a material escrito e Aprendizagem formal.

Nota 2: A mediana e a amplitude (Min-Max) são as estatísticas robustas à assimetria da distribuição.

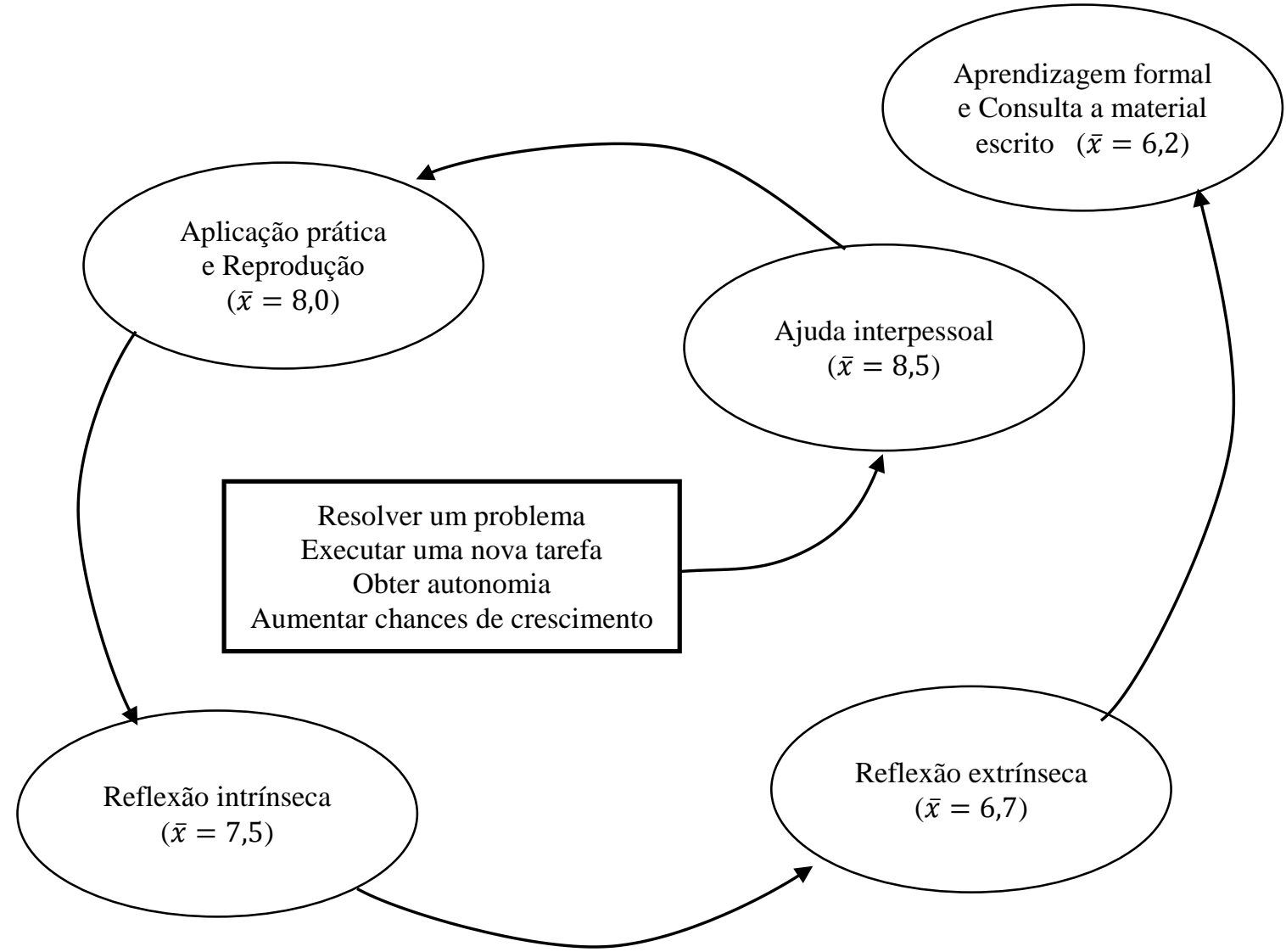

Figura 4 - Prioridade de uso das estratégias de aprendizagem Fonte: Resultados da pesquisa.

REAd | Porto Alegre - Edição 83 - N 1 - Janeiro/Abril 2016 - p. 166-192 


\section{Eduardo Jardim Ushiro \& Diógenes de Souza Bido}

Nota 1: Aqui foi usada a mesma representação gráfica de Pantoja e Borges-Andrade (2009, p.57), na qual as estratégias mais intensamente utilizadas encontram-se mais próximas das finalidades da aprendizagem (centro), enquanto as estratégias menos utilizadas encontram-se mais distantes.

Nota 2: Onde há duas estratégias juntas, significa que as diferenças de uso entre elas não eram significantes ( $\mathrm{p}>$ $0,05$ no teste de Wilcoxon). Elipses diferentes significa que as diferenças eram significantes ( $\mathrm{p}<0,05)$.

Nota 3: Para interpretar as médias, é preciso lembrar que a escala era de 1 a 10, onde: 5 a $6=$ faço às vezes, 7 a 8 $=$ faço muito e 9 a 10 = faço sempre.

Seja qual for a finalidade (Resolver um problema, Executar uma nova tarefa, Obter autonomia ou Aumentar as chances de crescimento) a primeira estratégia que os trabalhadores usam é a Ajuda interpessoal, e em segundo lugar há um empate entre a Aplicação prática e a Reprodução. Consulta a material escrito e Aprendizagem formal são as estratégias menos usadas, de um modo geral, mas também são aquelas em que há maior variação no uso.

\section{CONSIDERAÇÕES FINAIS}

Os resultados obtidos nesta pesquisa demonstraram que as estratégias de aprendizagem utilizadas por trabalhadores de uma linha de produção do ramo automotivo são as mesmas para as quatro finalidades apresentadas, ou seja, as práticas que proporcionam seu aprendizado, representadas pelas sete estratégias, não apresentaram variação significativa, seja para resolver um problema, executar uma nova tarefa, obter autonomia ou aumentar as chances na empresa. A partir desse resultado, pode-se concluir que os respondentes não distinguem suas estratégias para aprender em função de finalidades, aplicando-as independentemente dos motivos que cercam suas rotinas na empresa.

Holman et al. (2012) confirmaram que quanto mais frequentemente os indivíduos lidam com problemas difíceis de serem resolvidos (problem demand), mais eles usarão estratégias de aprendizagem (cognitivas e comportamentais), porém, eles tinham especulado (não testaram) que a estratégia de aprendizagem seria alinhada ao problema que o indivíduo estivesse lidando, neste sentido, nossa pesquisa complementa os resultados deles, pois, nossos resultados indicam que a estratégia de aprendizagem utilizada estava alinhada a fatores contextuais, e não ao problema em si.

O fato da ajuda interpessoal ser a estratégia mais utilizada pode ser explicado por ser um recurso que propicia ao trabalhador uma resposta prática e confiável, possibilitando tirar dúvidas rapidamente e de fácil compreensão da linguagem na comunicação. Esta prática também propicia a troca de informações em outros campos adjacentes ao trabalho junto a 


\section{ESTRATÉGIAS DE APRENDIZAGEM EM FUNÇÃO DA FINALIDADE PARA O APRENDIZADO: UM ESTUDO COM TRABALHADORES DA LINHA DE PRODUÇÃO DE UMA EMPRESA DO RAMO AUTOMOTIVO}

clientes, fornecedores, sindicatos e que não representam somente a essência das tarefas do cargo.

Confirmando a descrição de Illeris (2004), o processo de interação social do indivíduo desenvolve um fluxo contínuo, impulsionando a aprendizagem por meio de opiniões, explicações, padrões de comportamento, percepções e impressões recebidas nas mais variadas formas.

Outra explicação refere-se ao fato de muitas das atividades estarem ligadas a risco de acidentes, altos níveis de qualidade e problemas com meio ambiente, sendo assim, consultar colegas mais experientes ou o próprio chefe, proporciona ao empregado maior segurança na informação obtida por se tratar de uma referência prática sobre o que os demais executam.

Adicionalmente, esta prática atende ainda à expectativa nas organizações de maior colaboração entre os indivíduos (LESLIE et al.,1998). Quando indivíduos percebem que seus chefes e colegas apoiam a aplicação de novas aprendizagens no trabalho, e entendem que tal aplicação é vantajosa, passam a ser mais pró-ativos em comportamentos de transferência de aprendizagem. (COELHO JR.; MOURÃO , 2011).

Ainda dentre as estratégias mais utilizadas, aplicação prática e reprodução ficaram empatadas em segundo lugar e podem ser explicadas, respectivamente, pela natureza operacional das atividades e pela alta padronização dos processos executados. Ambientes com alto nível operacional de tarefas demandam a prática constante dos procedimentos para atingir melhores níveis de desempenho. Ao mesmo tempo, um alto nível de padronização requer que processos sejam executados da mesma forma e em conformidade com quesitos de qualidade, promovendo a estratégia reprodução como uma prática, até de certa forma, esperada aos empregados nesses cargos.

A consulta a material escrito configurou-se como uma das últimas opções e pode ser explicada em virtude do próprio ambiente físico não proporcionar boas condições para esta estratégia. Alto nível de ruído, baixa luminosidade ou exposição ao sol em alguns locais, altas temperaturas, exposição constante a pó, óleo, reagentes químicos, entre outros, são comuns a estes profissionais.

Uma segunda explicação refere-se às dúvidas que materiais escritos geram por apresentarem, por vezes, linguagem extremamente técnica e não serem didáticos o suficiente, dificultando a transposição do texto com a prática; além de não serem, muitas vezes, atualizados o suficiente para acompanhar as mudanças nas atividades.

REAd | Porto Alegre - Edição 83 - N 1 - Janeiro/Abril 2016 - p. 166-192 


\section{Eduardo Jardim Ushiro \& Diógenes de Souza Bido}

Uma terceira explicação refere-se à distribuição do tempo dos empregados na empresa, a qual espera que os profissionais estejam o tempo todo disponíveis para a execução das atividades, tornando mais difícil estudar um material escrito, o que demanda mais tempo do que consultar outras pessoas. A aprendizagem formal também se apresentou como uma das estratégias menos utilizada. Tal resultado pode ter sido influenciado pelo fato da verba para cursos ter sido quase inteiramente cortada 24 meses antes de a pesquisa ocorrer. O nível de escolaridade (cerca de $64 \%$ dos respondentes possuem $2^{\circ}$ grau completo ou nível técnico) também pode estar relacionado com a aplicação menos frequente desta estratégia.

Este foi um dos dois fatores constatados pelos autores que podem ter influenciado as respostas obtidas. Além da redução dos cursos, a pesquisa foi realizada logo após um programa de demissão voluntária, no qual cerca de 1.500 empregados foram desligados, gerando assim insegurança nos respondentes em oferecer informações sobre suas práticas individuais, mesmo que tenha sido explicado a todos de que a pesquisa tinha fins acadêmicos, sem vínculo com a empresa.

Mediante a constatação de que a ajuda interpessoal é a estratégia mais utilizada, uma recomendação para a empresa seria criar mais oportunidades de interação e comunicação entre esta categoria de empregados, possibilitando uma maior e melhor troca de informações, aprendizados e lições entre os mesmos, porém, o fato da amostra utilizada não ser probabilística, inviabiliza qualquer generalização dos resultados, por isso, antes de se propor ações mais concretas para toda a empresa, nossa recomendação vai mais no sentido de aprofundar a pesquisa, por exemplo: (1) aplicar a mesma pesquisa durante um período sem restrições aos meios de aprendizagem formal (cursos) e distante de ondas de desligamento de empregados, desfazendo assim possíveis influências nas respostas obtidas; (2) aplicar uma pesquisa baseada no modelo aqui proposto e junto ao mesmo público, entretanto, utilizandose metodologia qualitativa, para confirmar se, de fato, as estratégias utilizadas são as mesmas para todas as finalidades e (3) aplicar esta mesma pesquisa em profissionais com nível de escolaridade mais elevado e que atuam em outros ramos a fim de se comparar se as estratégias utilizadas são as mesmas, por exemplo, complementando os achados de Silva e Leite (2014) em relação à aprendizagem de professores universitários.

Outra possibilidade de extensão desta pesquisa é correlacionar as estratégias utilizadas com a importância que os empregados atribuem àquilo que eles aprendem (BIDO et al. 2011), procurando entender se aqueles que atribuem maior importância ao aprendizado contínuo usam estratégias específicas com maior intensidade para este fim.

REAd | Porto Alegre - Edição 83 - N 1 - Janeiro/Abril 2016 - p. 166-192 


\section{ESTRATÉGIAS DE APRENDIZAGEM EM FUNÇÃO DA FINALIDADE PARA O APRENDIZADO: UM ESTUDO COM TRABALHADORES DA LINHA DE PRODUÇÃO DE UMA EMPRESA DO RAMO AUTOMOTIVO}

O fato de termos conseguido mensurar as seis estratégias informais de aprendizagem (validade convergente, discriminante e confiabilidade) demanda novas pesquisas no sentido de avaliar a utilidade do construto como preditor de outros construtos, ou seja, a validade de critério (NETEMEYER; BEARDEN; SHARMA, 2003) ou como mediador em um modelo de causas e consequências (validade nomológica), que são exemplificados a seguir.

Holman et al. (2012) confirmaram a importância das estratégias informais de aprendizagem no local de trabalho como promotoras do processo de inovação dos indivíduos (geração, promoção e implementação de ideias), entretanto, eles modelaram as estratégias de aprendizagem como um construto bidimensional (estratégias cognitivas e comportamentais), talvez o modelo com seis dimensões descrevam de forma mais precisa o processo de inovação individual.

Isidro-Filho et al. (2013) modelaram as estratégias informais de aprendizagem em quatro dimensões (agrupou a busca de ajuda interpessoal com a aplicação prática; e reflexão intrínseca com a extrínseca) para prever as competências profissionais de funcionários de hospitais. Será que o modelo com seis dimensões seria mais esclarecedor do processo de desenvolvimento dessas competências?

Finalmente, após assinalarmos a importância das estratégias informais de aprendizagem, Crouse et al. (2011) apresentam uma revisão extensiva de facilitadores e barreiras da aprendizagem no local de trabalho, que podem ser úteis para a elaboração de modelos, que testem a validade nomológica do construto com seis dimensões.

\section{REFERÊNCIAS}

ARAMO-IMMONEN, H.; KOSKINEN. K. U.; PORKKA P. L. The significance of formal training in project-based companies. International Journal of Managing Projects in Business. v.4, n.2, p.257-273, 2011.

BIDO, D. S.; GODOY, A. S.; FERREIRA, J. F.; KENSKI, J. M.; SCARTEZINI, V. N. Examinando a relação entre aprendizagem individual, grupal e organizacional em uma instituição financeira. REAd - Revista Eletrônica de Administração, Edição 68, n.1, p.58$85,2011$.

BRANDÃO, H. P.; BORGES-ANDRADE, J. E. Desenvolvimento e Validação de uma Escala de Estratégias de Aprendizagem no Trabalho. In: XXXIII Encontro da ANPAD EnANPAD. Anais... São Paulo, ANPAD, 2009, p.1-16. 
Eduardo Jardim Ushiro \& Diógenes de Souza Bido

BROWN, T. A. Confirmatory Factor Analysis for Applied Research. New York: The Guilford Press, 2006.

CAMILLIS, P. K.; ANTONELLO, C. S. Um estudo sobre os processos de aprendizagem dos trabalhadores que não exercem função gerencial. RAM - Revista de Administração

Mackenzie, v.11, n.2, p.1-39, 2010.

COELHO JR, F. A.; MOURÃO, L. Suporte à aprendizagem informal no trabalho: uma proposta de articulação conceitual. RAM - REVISTA DE ADMINISTRAÇÃO MACKENZIE, v.12, n.6, p.1-31, 2011.

COHEN, J. Statistical Power Analysis for the Behavioral Sciences. 2nd ed. New York: Psychology Press, 1988.

CONLON, T. J. A review of informal learning literature, theory and implications for practice in developing global professional competence. Journal of European Industrial Training. Minnesota, v. 28, n.2/3/4, p. 283-295, 2003.

CONTE, D. L. Estratégias de aprendizagem informal e a aprendizagem dos profissionais de enfermagem - um estudo correlacional em hospitais. São Paulo, 2011. 92p. Dissertação (Mestrado em Administração de Empresas). Programa de Pós-graduação em Administração de Empresas, Universidade Presbiteriana Mackenzie.

CROSS; J. Informal Learning: rediscovering the natural pathways that inspire innovation and performance. San Francisco: Pfeiffer, 2007.

CROUSE, P.; DOYLE, W.; YOUNG, J. D. Workplace learning strategies, barriers, facilitators and outcomes: a qualitative study among human resource management practitioners. Human Resource Development International, v. 14, n. 1, p. 39-55, 2011.

DIRANI, K. M. Professional training as a strategy for staff development. European Journal of Training and Development. v.36, n.2/3, p.158-178, 2011.

ELKJAER, B. Organizational learning: the 'third way'. Management Learning, v.35, n.4, p.419-434, 2004.

FAUL, F.; ERDFELDER, E.; LANG, A.-G.; BUCHNER, A. G*Power 3: a flexible statistical power analysis program for the social, behavioral, and biomedical sciences. Behavior Research Methods, v.39, n.2, p.175-91, 2007.

HAIR JR., J. F.; HULT, G. T. M.; RINGLE, C. M.; SARSTEDT, M. A Primer on Partial Least Squares Structural Equation Modeling (PLS-SEM). Thousand Oaks, CA: Sage Publications, Inc., 2014.

HOLMAN, D.; EPITROPAKI, O.; FERNIE, S. Understanding learning strategies in the workplace: A Factor Analytic Investigation. Journal of Occupational and Organizational Psychology, v.74, p.675-681, 2001. 


\section{ESTRATÉGIAS DE APRENDIZAGEM EM FUNÇÃO DA FINALIDADE PARA O APRENDIZADO: UM ESTUDO COM TRABALHADORES DA LINHA DE PRODUÇÃO DE UMA EMPRESA DO RAMO AUTOMOTIVO}

HOLMAN, D.; TOTTERDELL, P.; AXTELL, C.; et al. Job Design and the Employee Innovation Process: The Mediating Role of Learning Strategies. Journal of Business and Psychology, v. 27, n. 2, p. 177-191, 2012.

ILLERIS, K. A model for learning in working life. Journal of Workplace Learning, v.16, n.8, p.431-441, 2004.

ISIDRO-FILHO, A.; GUIMARÃES, T. D. A.; PERIN, M. G.; LEUNG, R. C. Workplace learning strategies and professional competencies in innovation contexts in Brazilian hospitals. BAR - Brazilian Administration Review, v. 10, n. 2, p. 121-134, 2013.

KNOWLES, M. S.; HOLTON III, E. F.; SWANSON, R. A. The Adult Learner: The definitive classic in adult education and human resource development. 6 ed. San Diego: Elsevier, 2005.

KOCK, H.; ELLSTRÖM, P. Formal and integrated strategies for competence development in SMEs. Journal of European Industrial Training. v.35, n.1, p.71-88, 2010.

LESLIE, B.; ARING, M. K.; BRAND, B. Informal learning: The new frontier of employee and organizational development. Economic Development Review, v.15, n.4, p.12-18, 1998.

MARSICK, V. J.; WATKINS, K. E. Informal and Incidental Learning. New Directions for Adult and Continuing Education, v.89, p. 25-34, 2001.

MERRIAM, S. B. Andragogy and Self-Directed Learning: Pillars of Adult Learning Theory. New Directions for Adult and Continuing Education, v.89, p.3-13, 2001.

NETEMEYER, R. G.; BEARDEN, W. O.; SHARMA, S. Scaling procedures: issues and applications. Thousand Oaks: Sage Publications, 2003.

PANTOJA, M. J. Estratégias de Aprendizagem no Trabalho e Percepções de Suporte à Aprendizagem Contínua - uma análise multinível, 2004. 211p. Tese (Doutorado em Psicologia). Programa de Pós-Graduação em Psicologia, Universidade de Brasília. Brasília.

PANTOJA, M. J.; BORGES-ANDRADE, J. E. Estratégias de Aprendizagem no Trabalho em Diferentes Ocupações Profissionais. RAC-Eletrônica, v.3, n.1, p. 41-62, 2009.

RINGLE, C. M.; WENDE, S.; WILL, S. SmartPLS 2.0 (M3) Beta. Hamburg, 2005. Disponível em: < https://www.smartpls.com/smartpls2>. Acesso em 30/06/2015.

SILVA, M. A. B.; LEITE, N. R. P. Aprendizagem e mudança organizacional em uma instituição de ensino superior em administração. REAd - Revista Eletrônica de Administração, Edição 77, n.1, p.195-224, 2014.

WARR, P.; DOWNING, J. Learning strategies, learning anxiety and Knowledge acquisition. British Journal of Psychology, v.91, p.311-333, 2000. 